\title{
How Long Does It Take to Become a Competent Family Physician?
}

\author{
Robin O. Winter, MD, MMM
}

No one knows for sure how long it takes to train a competent family physician. Family medicine, internal medicine, and pediatrics all require a 3 -year residency before board certification in the United States. In Canada, only 2 years are required for family medicine board certification. Before 1969, general practice training in the United States was also only a 2-year curriculum before it was extended to 3 years as it evolved into family medicine. Health care has changed dramatically since 1969, with an explosion of medical knowledge and new technology that challenges us to once again question the proper length of a family medicine residency education. Marguerite Duane, Larry Green, Susan Dovey, and their coauthors try to answer this question in 2 articles on the length and content of family medicine residency training. ${ }^{1,2}$

The first, published in 2002, was based on a simultaneous survey of family medicine residency directors, first-year residents in the programs of the sampled residency directors, and family physicians due for their first board recertification examination. The survey solicited their opinions about the length and content of family medicine residencies. The majority of respondents in each group favored the current 3-year model. However, 27\% of residency directors, $32 \%$ of first-year residents, and $28 \%$ of recertifying family physicians supported adding a fourth year to residency training. All 3 groups agreed that the breadth and depth of the residency experience would have to be expanded to justify adding another year, but the only topics that they agreed warranted more training were officebased procedures and sports medicine. The most

Submitted, revised, 9 July, 2004.

From the JFK Family Practice Residency, UMDNJRobert Wood Johnson Medical School, Edison, New Jersey. Address correspondence to Robin O. Winter, MD, MMM, JFK Family Practice Residency Program, 65 James St., Edison, NJ 08818. E-mail: rwinter@solarishs.org. significant barriers they identified to adding a fourth year to residency education included the lack of agreement that it is necessary, financing the expansion, and lost opportunity costs for residents during the fourth year. ${ }^{1}$

For the follow-up study, Duane et al chose to resurvey only the resident group from their 2002 article. As first-year residents, this group had the largest percentage of respondents interested in a 4-year residency (32\%), and they wanted to determine whether their opinions had changed as thirdyear residents. One of the weaknesses of the follow-up study is that it includes responses from only 280 of the original 533 respondents from the 2002 study. The responders in the current study have similar demographics compared with those lost to follow-up and the nonresponders. However, the current study's findings represent only $52.3 \%$ of the 2002 study's first-year resident responders, and only $28 \%$ of the 997 first-year residents initially surveyed for the 2002 study. Apart from this limitation, the follow-up study found remarkable consistency from first to third year in the residents' opinions concerning the length of their training. ${ }^{2}$

As third-year residents, $37 \%$ of the respondents favored 4-year family medicine residency programs compared with $32 \%$ as first-year residents. The third-year residents supported a fourth year of training because of the broad scope of family medicine, the perceived need for more training in certain clinical areas, such as office procedures, and the longer duration of training for other medical specialists. However, this modest increase in support by third-year residents for a 4-year curriculum may represent the natural insecurity of graduating residents facing independent practice. This insecurity could still be present after a fourth year of training. Financial barriers and the negative impact of having to commit to a fourth year of residency were still seen as significant impediments to adding a fourth year of training. ${ }^{2}$ 
In 1988, Ferentz et al published a study asking program directors, recent graduates, and third-year residents whether family medicine residency should be extended to 4 years. They found that $20 \%$ of program directors, $32 \%$ of recent graduates, and $34 \%$ of third-year residents supported expansion. ${ }^{3}$ This consistent, substantial minority support for 4-year family medicine residency programs leads Duane et al to propose a period of experimentation to determine the proper length of training for family medicine.

The primary care specialties of family medicine, general internal medicine, and pediatrics have all recently published position papers on the future of their disciplines. It is interesting to note the differences in their recommendations concerning the length of specialty training. The recommendation from the Future of Family Medicine project regarding residency education encourages 5 to 10 years of experimentation in competency-based education and an evaluation strategy "to determine the relative merits of 3-year verses 4-year training programs." " The Future of General Internal Medicine proposes expanding general internal medicine residency training to 4 years. The first 2 years of general internal medicine residency would stay essentially the same. The third year would provide focused experiences with specialized populations (geriatrics, HIV, etc) and the fourth year would be for "mastery" leading to a certificate of added qualifications in specific areas such as geriatrics, hospital medicine, etc. ${ }^{5}$ The Future of Pediatric Education II Project recommends maintaining 3-year pediatric residencies, but goes on to say that "there should be a future reassessment of the length of training after the development of core competencies and the evaluation of educational outcomes." Practitioners in each of the primary care specialties perceive a need to examine the current structure and content of their residencies, but each has its own approach as to how to accomplish that. Only general internal medicine has a strong recommendation to expand its residency education to 4 years.

The family medicine and pediatric recommendations both focus on competency-based education and the evaluation of educational outcomes. In an article title Competency-Based Education in Family Practice, Bell et $\mathrm{al}^{7}$ state "A true competency-based residency curriculum would make the duration of the residency dependent on the time needed to achieve mastery." They proposed 26 competencies grouped into 5 categories and called for the development of a national, core competency-based curriculum that is flexible enough to facilitate regional and programmatic variations. ${ }^{7}$ However, since the publication of this article in 1997, there is still no agreement on the content of a national, core competency-based family medicine residency curriculum. The Future of Family Medicine project further defines the core values, key characteristics, and "Basket of Services" family physicians should offer, but educators still have to agree on this content and translate it into measurable, educational competencies. Until we know exactly what we want to teach, it is impossible to determine how long it should take to learn it. Although expert opinion and surveys provide important insight into the proper duration of residency education, they do not provide sufficient evidence upon which to base a decision about either reducing residency programs to 2 years, as proposed by Zweifler, ${ }^{8}$ or extending them to 4 years, as discussed by Saultz and David in Family Medicine.

In addition to the challenge of defining a core competency-based family medicine curriculum, it is equally important to quantify and measure the degree to which mastering the curriculum results in residents providing higher quality patient care. Family Medicine recently published a series of special articles on assessing and measuring resident competence. In an essay accompanying the series, Barry Weiss, the journal's editor, observes "I don't see many papers, however, either submitted to Family Medicine or published elsewhere, that use objective measures to assess whether the result of our teaching is the production of physicians who are more capable and competent." ${ }^{\text {"T }}$ The ACGME Outcome Project is also challenging residency educators to demonstrate evidence that educational outcomes based on competency-based learning enable residents to be more competent physicians. ${ }^{11}$ This call for evidence-based education is analogous to the current demand for evidence-based clinical medicine and represents one of the greatest challenges facing residency faculty.

Even if competency-based educational outcomes provided enough evidence to justify changing the length of family medicine residency education, there would still be significant barriers to change. The financial implications of either shortening or lengthening residency training would make any change difficult. In addition, the articles by Duane 
et $\mathrm{al}^{1,2}$ highlight the lack of consensus for changing residency education from its current 3 years. Furthermore, a true competency-based residency curriculum would not have a fixed duration but would vary depending on the time it took each resident to demonstrate competence. Administering such a program would be virtually impossible.

We cannot answer the question, "How long does it take to become a competent family physician?" based on the current state of the art for residency education. The time is right for the 7 national family medicine organizations that initiated the Future of Family Medicine project to launch a follow-up project to create a core competency-based family medicine curriculum using the findings from the Future of Family Medicine. After we have defined exactly what we want to teach, we can go on to measure the effectiveness of that teaching. Then, and only then, will we have the evidence to truly determine how long family medicine residency education should be.

\section{References}

1. Duane M, Green LA, Dovey S, Lai S, Graham R, Fryer GE. Length and content of family practice residency training. J Am Board Fam Pract 2002;15: 201-8.

2. Duane M, Dovery SM, Klein LS, Green LA. Follow-up on family practice residents' perspectives on length and content of training J Am Board Fam Pract 2004;17:377-83.

3. Ferentz KS, Sobal J, Colgan R. Family medicine resident training - three or four years? J Fam Pract 1988;26:415-20.

4. Martin JC, Avant RF, Bowman MA, et al. The Future of Family Medicine: a collaborative project of the family medicine community. Ann Fam Med 2004;2 Suppl 1:S3-32. Available at: http://www. annfammed.org/content/vol2/suppl_1.

5. Society of General Internal Medicine [homepage on the Internet]. Washington DC: Society of General Internal Medicine; 2003 [cited 2004 May 24]. SGIM Task Force on the Domain of General Internal Medicine. The Future of General Internal Medicine; [about 2 screens]. Available from: http://www.sgim. org/futureofGIMreport.cfm.

6. American Academy of Pediatrics [homepage on the Internet]. Elk Grove Village (IL): American Academy of Pediatrics; 2004 [cited 2004 May 24]. The Future of Pediatric Education II (FOPE II) Project. Organizing pediatric education to meet the needs of infants, children, adolescents, and young adults in the 21 st century; [about 2 screens]. Available from: http://www.aap.org/profed/fope1.htm.

7. Bell HS, Kozakowski SM, Winter RO. Competencybased education in family practice. Fam Med 1997; 29:696-700.

8. Zweifler J. Why we should reduce family practice training to two years. Acad Med 2003;78:885-7.

9. Saultz J, David A. Is it time for a 4-year family medicine residency? Fam Med 2004;36:363-6.

10. Weiss BD. Are we competent to assess competence? Fam Med 2004;36:214-16.

11. Accreditation Council for Graduate Medical Education [homepage on the Internet]. Chicago: Accreditation Council for Graduate Medical Education; 2001 [cited 2004 May 24]. ACGME Outcome Project; [about 10 screens]. Available from: http// www.acgme.org/Outcome. 